\title{
Cellular Sites for Dynorphin Activation of $\kappa$-Opioid Receptors in the Rat Nucleus Accumbens Shell
}

\author{
Adena L. Svingos, Eric E. O. Colago, and Virginia M. Pickel \\ Department of Neurology and Neuroscience, Division of Neurobiology, Cornell University Medical College, New York, \\ New York 10021
}

\begin{abstract}
The nucleus accumbens (Acb) is prominently involved in the aversive behavioral aspects of $\kappa$-opioid receptor (KOR) agonists, including its endogenous ligand dynorphin (Dyn). We examined the ultrastructural immunoperoxidase localization of KOR and immunogold labeling of Dyn to determine the major cellular sites for KOR activation in this region. Of $851 \mathrm{KOR}-$ labeled structures sampled from a total area of $10,457 \mu \mathrm{m}^{2}$, $63 \%$ were small axons and morphologically heterogenous axon terminals, $31 \%$ of which apposed Dyn-labeled terminals or also contained Dyn. Sixty-eight percent of the KOR-containing axon terminals formed punctate-symmetric or appositional contacts with unlabeled dendrites and spines, many of which received convergent input from terminals that formed asymmetric synapses. Excitatory-type terminals that formed asymmetric synapses with dendritic spines comprised $21 \%$ of the KOR-
\end{abstract}

The nucleus accumbens (Acb) is a brain region critically involved in the locomotor and aversive behaviors associated with dynorphin (Dyn) and other $\kappa$-opioid receptor (KOR) ligands. Selective KOR agonists, such as U50488 and U69593, attenuate basal and morphine-induced locomotor activity (Di Chiara and Imperato, 1988; Pearl and Glick, 1996). Moreover, local infusion of KOR agonists produces conditioned place aversion that is abolished by Acb lesions (Bals-Kubik et al., 1993; Shippenberg et al., 1993). Rewarding behaviors, such as morphine-induced place preference, are attenuated by KOR activation (Funada et al., 1993). In this regard, the KOR antagonist nor-binaltorphimine potentiates morphine withdrawal symptoms, including withdrawal-induced place aversion (Spanagel et al., 1994).

The behavioral effects of KOR ligands are thought to occur mainly via presynaptic KOR modulation of transmitter release. Extracellular dopamine levels in the striatum are modulated by KOR agonists, including Dyn (Di Chiara and Imperato, 1988; Mulder et al., 1989; Heijna et al., 1990; Spanagel et al., 1992; Shippenberg et al., 1996). In addition, KOR activation decreases glutamate and acetylcholine transmission, presumably via decreased transmitter release (Mulder et al., 1984; Lapchak et al., 1989; Wagner et al., 1992; Schoffelmeer et al., 1997; Rawls and McGinty, 1998). Effector systems underlying KOR modulation of

\footnotetext{
Received Sept. 17, 1998; revised Dec. 3, 1998; accepted Dec. 8, 1998.

This work was supported by the National Institute on Drug Abuse Grant DA04600 to V.M.P. We wish to thank Dr. Charles Chavkin for his generous donation of the $\kappa$-opioid receptor antibody, Dr. Carrie T. Drake for her helpful comments on this manuscript, and Dr. Sundari Periasamy for her invaluable technical assistance.

Correspondence should be addressed to Dr. Adena L. Svingos, Department of Neurology and Neuroscience, Division of Neurobiology, Cornell University Medical College, 411 East 69th Street, New York, NY 10021.

Copyright (C) 1999 Society for Neuroscience $\quad 0270-6474 / 99 / 191804-10 \$ 05.00 / 0$
}

immunoreactive profiles. Dendritic spines within the neuropil were the major nonaxonal structures that contained KOR immunoreactivity. These spines also received excitatory-type synapses from unlabeled terminals and were apposed by Dyncontaining terminals. These results provide ultrastructural evidence that in the Acb shell (AcbSh), KOR agonists play a primary role in regulating the presynaptic release of Dyn and other neuromodulators that influence the output of spiny neurons via changes in the presynaptic release of or the postsynaptic responses to excitatory amino acids. The cellular distribution of KOR complements those described previously for the reward-associated $\mu$-and $\delta$-opioid receptors in the Acb shell.

Key words: aversion; opiate; nucleus accumbens; ultrastructure; electron microscopy; immunoreactivity neurotransmitter release or efficacy are thought to occur via changes in ion channel conductance at presynaptic sites (Attali et al., 1989; Fan et al., 1991; Heijna et al., 1992; Grudt and Williams, 1993; Rhim and Miller, 1994) or via alterations in postsynaptic potentials (Yuan et al., 1992).

Autoradiographic examination of KOR at the light and electron microscopic levels shows distribution patterns distinct from that of $\mu$ - and $\delta$-opioid receptors (MOR and DOR) in most brain regions (Mansour et al., 1987; Tempel and Zukin, 1987; Jomary et al., 1992). The Acb, however, shows prominent immunocytochemical distributions of the three opioid receptors, revealing a patchy distribution of KOR, comparable with that of Dyn (McGinty et al., 1994; Arvidsson et al., 1995; Mansour et al., 1996). In the present study, we used electron microscopic immunocytochemistry to determine within the shell compartment of the rat Acb (AcbSh) (1) the cellular and subcellular distributions of KOR and (2) the spatial relationship between KOR and its endogenous ligand Dyn (Chavkin et al., 1982). Our results provide the first ultrastructural evidence of the major involvement of KOR in presynaptic transmitter release from morphologically and perhaps chemically heterogenous axon terminals, including those containing Dyn. We also show that KOR immunoreactivity is present within dendritic spines that (1) are postsynaptic to unlabeled terminals forming excitatory-type synapses and (2) appose Dyn-containing terminals. These results suggest that in the AcbSh, KOR activation by locally released Dyn produces major changes in the presynaptic release of Dyn and other neuromodulators, which can regulate either the presynaptic release of or the postsynaptic response to excitatory amino acids. These data, together with our previous studies of MOR and DOR (Svingos et al., 1996, 1998), the primary mediators of opiate reward, indicate 
that opioids active at their respective receptors target complementary cellular sites within the AcbSh.

\section{MATERIALS AND METHODS}

Antibody specificity. A well characterized anti-peptide antiserum against the cloned rat KOR was used. A polyclonal antiserum, corresponding to amino acids $371-380$ of the intracellular C-terminal domain, was generated in rabbit (Drake et al., 1996; Appleyard et al., 1997). The specificity of the affinity-purified KOR antibody was characterized by (1) ELISA, (2) Western blot analysis, (3) labeling of Xenopus laevis oocytes transfected with KOR, and (4) preadsorption of KOR-labeled tissue with the parent peptide.

A guinea pig polyclonal antiserum raised against Dyn was obtained from Peninsula Laboratories (Belmont, CA). The specificity of the Dyn antibody was shown by peptide absorption with the parent peptide. The Dyn immunoreactivity detected with this antiserum displayed a patchy distribution within the AcbSh, as seen in previous studies using other Dyn antisera (Fallon and Leslie, 1986).

Immunocytochemistry. Adult male Sprague Dawley rats were anesthetized with sodium pentobarbital $(100 \mathrm{mg} / \mathrm{kg}$, i.p.) and perfused through the ascending aorta with (1) $10 \mathrm{ml}$ of heparin (1000 U/ml) in saline, (2) $50 \mathrm{ml}$ of $3.75 \%$ acrolein (Polysciences, Warrington, PA) in a solution of $2 \%$ paraformaldehyde and $0.1 \mathrm{M}$ phosphate buffer (PB), $\mathrm{pH} 7.4$, and (3) $200 \mathrm{ml}$ of $2 \%$ paraformaldehyde. The brains were then removed and post-fixed for $30 \mathrm{~min}$ in $2 \%$ paraformaldehyde. After the brains were sectioned at $30-40 \mu \mathrm{m}$ on a vibratome, the tissue was treated with $1 \%$ sodium borohydride in $0.1 \mathrm{M}$ PB to remove excess aldehydes. Tissue sections were then freeze-thawed to enhance penetration of immunoreagents. For this, tissue was incubated in a cryoprotectant solution containing $25 \%$ sucrose and $2.5 \%$ glycerol in $0.05 \mathrm{M} \mathrm{PB}$ and then was immersed successively in (1) liquid freon, (2) liquid nitrogen, and (3) room temperature $\mathrm{PB}$. Tissue sections were then rinsed in $0.1 \mathrm{M} \mathrm{PB}$, followed by $0.1 \mathrm{~m}$ Tris-buffered saline (TBS), $\mathrm{pH}$ 7.6. Sections were incubated for $30 \mathrm{~min}$ in $1 \%$ bovine serum albumin in TBS to minimize nonspecific labeling.

For single-labeling experiments with the KOR antibody, tissue sections that were prepared as described above were incubated for $48 \mathrm{hr}$ at $4^{\circ} \mathrm{C}$ in primary antiserum (1:1500). For dual-labeling experiments, tissue sections were incubated in a solution containing the KOR antiserum (1:500) and the antibody against Dyn (1:2500). For immunoperoxidase detection of KOR, sections were incubated in (1) biotinylated goat anti-rabbit IgG (1:400; Vector Laboratories, Burlingame, CA) and (2) avidin-biotin complex (1:200) (Hsu et al., 1981). The peroxidase reaction product was visualized with $22 \mathrm{mg}$ of 3,3'-diaminobenzidine (Aldrich, St. Louis, MO) in $10 \mu \mathrm{l}$ of $30 \% \mathrm{H}_{2} \mathrm{O}_{2}$ and $100 \mathrm{ml}$ of TBS for $6 \mathrm{~min}$. All incubations were performed at room temperature (unless otherwise noted) with continuous agitation. Sections were rinsed with TBS between incubations.

The method of Chan et al. (1990) was used for pre-embedding immunoperoxidase and immunogold dual-labeling of the tissue. For immunogold-silver detection of Dyn, tissue sections that were processed for KOR were then (1) incubated for $2 \mathrm{hr}$ in colloidal gold $(1 \mathrm{~nm})$-labeled anti-guinea pig $\operatorname{IgG}(1: 50)$, (2) fixed for $10 \mathrm{~min}$ in $2 \%$ glutaraldehyde in PBS, and (3) reacted for 5-10 min with a silver solution (IntenSE kit; Amersham, Arlington Heights, IL).

For electron microscopic detection of the Dyn and/or KOR antisera, tissue sections were post-fixed with $2 \%$ osmium tetroxide in $0.1 \mathrm{M} \mathrm{PB}$ for $1 \mathrm{hr}$, dehydrated through graded ethanols and propylene oxide, and embedded in Epon 812 between two sheets of Aclar plastic (Leranth and Pickel, 1989). Ultrathin tissue sections $(40-50 \mathrm{~nm})$ were cut through the AcbSh at the levels of plates 11-13 of the rat brain atlas of Paxinos and Watson (1986). Thin sections were cut with a diamond knife (Diatome, Fort Washington, PA) and collected on copper mesh grids in serial order from the outer surface of the tissue. The sections were then counterstained with uranyl acetate and lead citrate (Reynolds, 1963) and examined with Phillips 201 or CM-10 electron microscopes.

Assessment of cellular elements. The classification of labeled cellular profiles was based on descriptions of Peters et al. (1991). Somata were identified by the presence of nuclei. Dendrites were recognized by the presence of postsynaptic densities and/or an abundance of endoplasmic reticulum and microtubules. Axons were between 0.1 and $0.5 \mu \mathrm{m}$ in diameter and rarely contained small synaptic vesicles (SSVs). Small axon terminals were between 0.5 and $1.0 \mu \mathrm{m}$ in diameter and contained a few SSVs. Large axon terminals contained a relative abundance of SSVs and were between 1.0 and $1.5 \mu \mathrm{m}$ in diameter. Synapses were characterized as either asymmetric (thin presynaptic and thick postsynaptic densities) or symmetric (equally thin pre- and postsynaptic densities) (Carlin et al., 1980; Hendry et al., 1983). Nonsynaptic contacts or appositions were defined as close membranous associations that lacked recognizable specializations but were not otherwise separated by astrocytic processes. "Perisynaptic" was defined as the area of the dendritic plasma membrane that was adjacent to the postsynaptic density. "Extrasynaptic" was defined as that area of the dendritic plasma membrane that was not adjacent to the synaptic junction.

Data analysis. The total field used for analysis of KOR-like immunoreactivity (KOR-LI) was taken from electron micrographs that were chosen based on the presence of labeling for the antigen(s) of interest and morphological integrity. The presence of KOR-labeled profiles was verified by examining serial tissue sections, whenever possible. In singly labeled tissue, the number of KOR-immunoreactive profiles representing specific neuronal (dendritic, axonal, or somatic) or glial compartments was determined by analysis of four to six vibratome sections taken from each of eight animals. From this tissue, we examined a total area of 4225 $\mu \mathrm{m}^{2}$ to determine the percent of the total KOR-labeled structures $(n=$ $851)$ that were present in each compartment. In dually labeled tissue sections from six animals, we examined the incidence of association between KOR- and Dyn-labeled profiles. For this analysis, we determined in an area of $6232 \mu \mathrm{m}^{2}$ the number of KOR-labeled structures in each compartment that contained Dyn or apposed Dyn-labeled structures $(n=145)$.

\section{RESULTS}

As shown in previous studies, KOR and Dyn immunoreactivities were seen in patchy light microscopic distributions within the ventromedial AcbSh shell (Fallon and Leslie, 1986; McGinty et al., 1994; Arvidsson et al., 1995; Mansour et al., 1996). Ultrastructural analysis of the more intensely labeled regions showed selective immunoperoxidase localization of KOR in many neuronal and in a few glial profiles. Of 851 KOR-labeled structures, $63 \%$ were small axons and morphologically heterogenous axon terminals. The remainder mainly were dendritic spines and dendrites (26\%). Dual labeling showed the presence of Dyn in axon terminals that apposed the KOR-immunoreactive profiles or contained KOR-LI.

\section{Morphologically heterogenous axon terminals and unmyelinated axons contain KOR immunoreactivity}

Of 540 KOR-containing axonal profiles, 54\% were identified as axon terminals on the basis of their size $(0.5-1.5 \mu \mathrm{m})$ and the presence of SSVs. Within axon terminals, the immunolabeling for KOR was associated with selective segments of the plasma membrane and with membranes of the SSVs (Fig. 1A). The labeled terminals were morphologically heterogenous with respect to size and synaptic specialization. Sixty-eight percent of all KORlabeled terminals were small $(0.5-1.0 \mu \mathrm{m})$ and formed punctatesymmetrical or appositional contacts with unlabeled dendrites and dendritic spines (Fig. $1 A$ ). The majority of the spines contacted by these KOR-containing axon terminals received convergent input from large unlabeled terminals that formed asymmetric excitatory-type synapses (Fig. $1 A$ ). Twenty-one percent of the KOR-immunoreactive terminals were larger $(1.0-1.5 \mu \mathrm{m}$ in diameter) and formed asymmetric synapses with unlabeled spines. Finally, $<4 \%$ of KOR-immunoreactive terminals were large and formed symmetric synapses with dendritic shafts. The shafts usually also received input from other large unlabeled terminals, forming mainly symmetric but also asymmetric junctions. Fortysix percent ( $n=247$ of 540) of all KOR-labeled axonal profiles were unmyelinated axons that were $<0.1 \mu \mathrm{m}$ in diameter. These axons either were isolated or were grouped in bundles with other KOR-labeled or unlabeled axons (Figs. $1 B, 2$ ). 

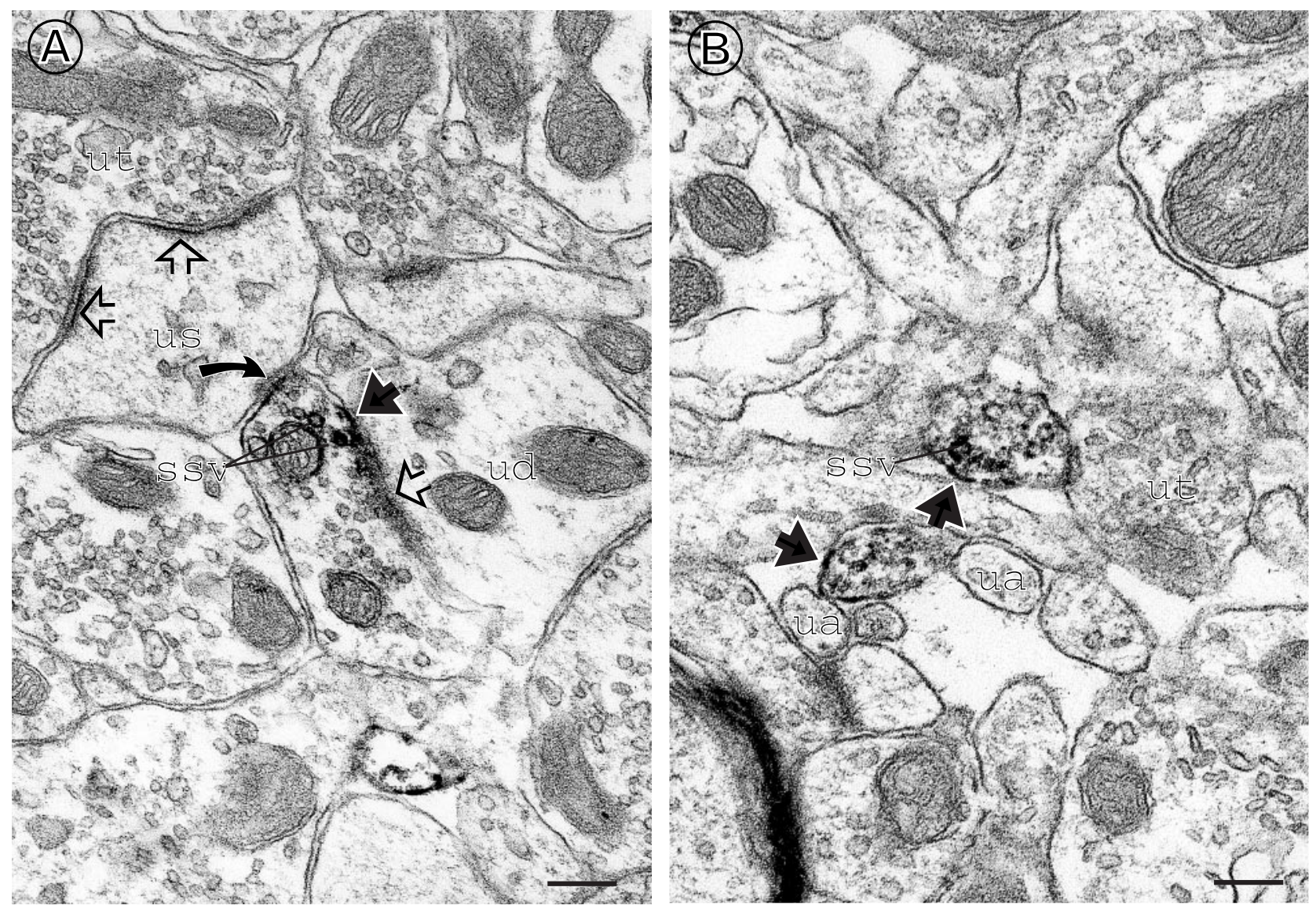

Figure 1. Electron micrographs showing KOR immunoreactivity localized within axon terminals and axons. $A$, The peroxidase reaction product for KOR is localized to a small perisynaptic segment of the plasma membrane (small filled arrow) and to membranes of some small synaptic vesicles (ssvs) within an axon terminal. The terminal forms a junction (open arrow) with an unlabeled dendrite ( $u d$ ) and a symmetric synapse (curved arrow) with an unlabeled dendritic spine $(u s)$. The unlabeled spine also receives a perforated asymmetric synapse (open arrows) from an unlabeled terminal ( $u t$ ). $B$, The axons show KOR labeling intensely localized to plasma and vesicular membranes (small filled arrows). The larger labeled axon in $B$ also shows peroxidase labeling in association with the membranes of ssvs. This axon is apposed to a $u t$. The smaller axon in $B$ also is adjacent to other unlabeled axons (ua), although the plasmalemmal appositions are less well defined. Scale bars, $0.2 \mu \mathrm{m}$.

\section{KOR-immunoreactive axons and terminals appose Dyn-labeled axon terminals or contain Dyn}

The prominent presynaptic localization of KOR also was seen in tissue sections that were dually labeled for KOR and Dyn. Although the majority of KOR-labeled axons were not recognizably associated with Dyn-containing terminals, 31\% (84 of 271) of these axons either apposed Dyn-labeled axon terminals or also colocalized Dyn immunoreactivity. Appositional contacts comprised approximately one-half of these associations and included KOR-immunoreactive axons, as well as small axon terminals (Fig. $2)$. Dyn-labeled terminals were large $(>0.5 \mu \mathrm{m}$ in diameter) and contained many SSVs and often one or more dense core vesicles (DCVs). Some of these vesicles were located near appositional contacts with unlabeled dendritic spines and dendrites. KOR immunoreactivity was not present along membranes of SSVs or portions of the plasma membrane that were immediately apposed by Dyn-labeled terminals (Fig. 2).

Approximately $27 \%$ of all associations between KOR and Dyn were axon terminals that contained both antigens. Dually labeled axon terminals were morphologically similar to the Dyncontaining terminals described above and contacted unlabeled dendrites (Fig. 3). In these terminals, KOR-LI also was similar to that in other axons, in which the labeling was associated with small segments of the plasma membrane and membranes of both SSVs and DCVs (Fig. 3). Within dually labeled axon terminals, the immunoreactivities for KOR and Dyn usually did not overlap.

\section{KOR immunoreactivity is present in dendritic spines that receive excitatory-type synapses and appose Dyn-labeled terminals}

Dendritic spines comprised $19 \%(n=161$ of 851$)$ of the profiles that contained peroxidase labeling for KOR. The peroxidase reaction product was diff usely distributed throughout these spines but appeared more densely located along plasma membranes (Fig. $4 A, B$ ). The identified spines were postsynaptic to unlabeled terminals forming asymmetric membrane specializations. These unlabeled terminals were up to $1.5 \mu \mathrm{m}$ in diameter and contained many loosely packed SSVs. In labeled spines, the postsynaptic densities (Fig. 4A) and the perisynaptic portions of the plasma membrane (Fig. 4B) were intensely immunoreactive for KOR. KOR immunoreactivity also was localized to discrete extrasynaptic sites along the plasma membrane that were apposed to unlabeled profiles, including glial processes, dendrites, and terminals (Fig. 4A,B). In singly labeled tissue, KOR- 

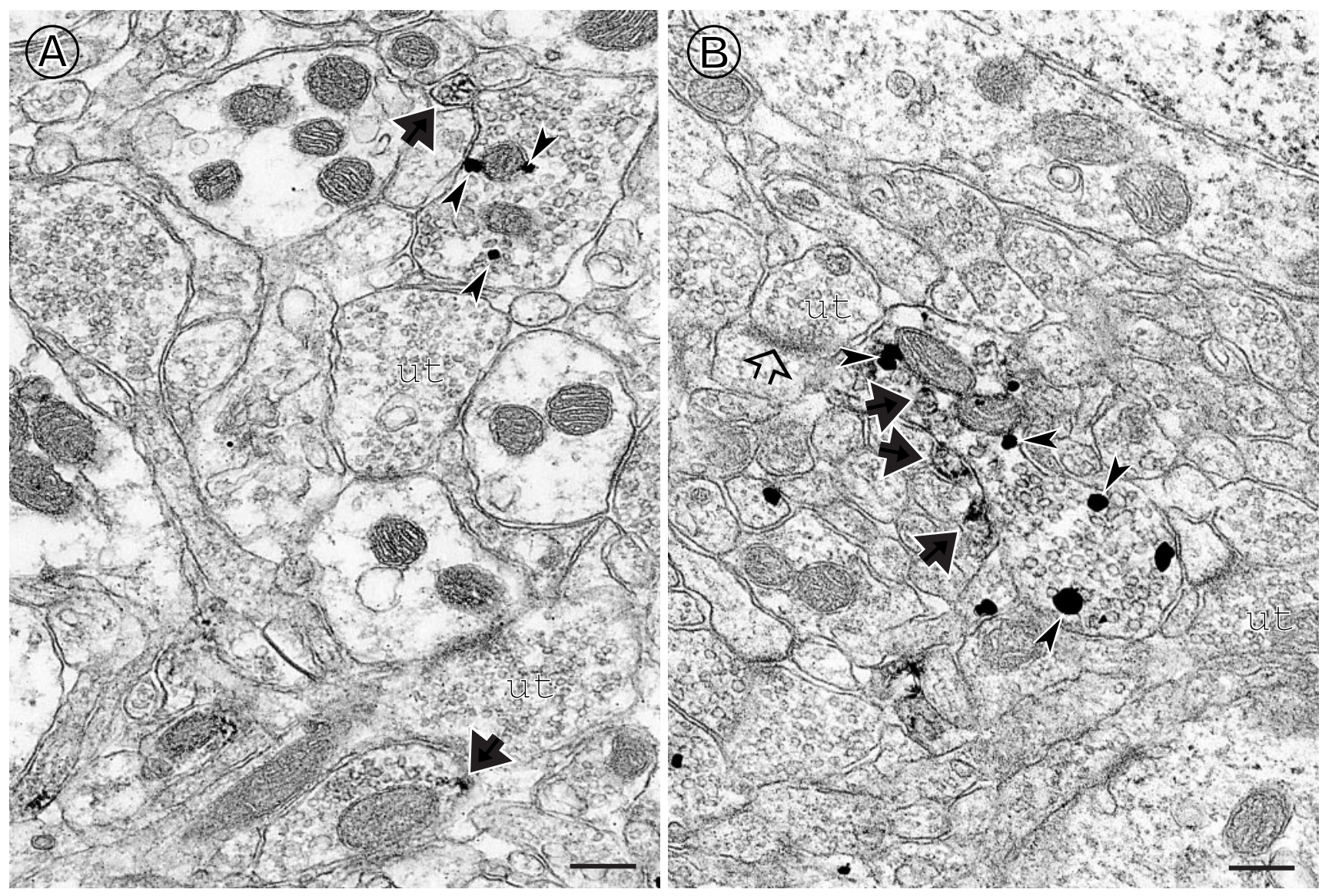

Figure 2. Immunoperoxidase labeling for KOR in small axons that appose terminals containing Dyn. A, A KOR-immunoreactive axon (upper small filled arrow) is apposed to a terminal that contains immunogold-silver particles for Dyn (arrowheads). Other unlabeled (ut) and lightly KOR-labeled terminals (lower small filled arrow) are seen within the neuropil. B, Small KOR-immunoreactive axons (lower small filled arrows) appose a large axon terminal containing immunoreactivity for KOR and Dyn. Within the dually labeled terminal, the KOR peroxidase reaction product (upper small filled arrow) appears more intensely localized to the membranes of large vesicles, whereas the immunogold-silver particles for Dyn (arrowheads) are dispersed within the cytoplasm. The diffuse peroxidase reaction product in this terminal is not seen in other apposed $u t$ that forms an unlabeled asymmetric synapse (open arrow). Scale bars, $0.24 \mu \mathrm{m}$.

immunoreactive spines also were contacted by other unlabeled terminals that contained DCVs (Fig. 4A), comparable with those seen in many Dyn-containing terminals. Dual labeling confirmed that at least some $(5 \%)$ of the apposed axons containing DCVs were immunoreactive for Dyn (Fig. 5). These Dyn-containing terminals also formed symmetric synapses with unlabeled dendrites (Fig. 5) but did not synapse with KOR-labeled dendrites.

\section{Somata and large dendrites are immunoreactive for KOR}

Less than $10 \%$ of the profiles containing KOR-LI were perikarya and large dendritic shafts ( $n=59$ of 851 KOR-labeled profiles). The paucity of KOR-labeled perikarya and proximal dendrites may reflect (1) the proportionally low number of somata and large dendrites in the neuropil, as compared with axons, terminals, and smaller dendritic shafts, and (2) the relatively low levels of KOR immunoreactivity within these larger profiles. KOR-containing somata generally had round nuclei and an abundance of cytoplasm, typical of spiny striatal neurons. Within perikarya and large dendrites, KOR-LI was localized mainly to membranes of cytoplasmic organelles, including trans-Golgi lamellae and smooth endoplasmic reticulum. In comparison with somata, which showed limited plasmalemmal KOR labeling, KOR-LI more often was associated with the plasma membrane of dendrites. Within these dendrites, KOR immunoreactivity was localized to discrete portions of the plasma membrane (Fig. 4A). KOR-labeled segments of dendritic plasma membranes often were apposed by unlabeled axon terminals or filamentous glial processes (Fig. 4A). Occasionally, KOR-LI was also seen along membranes of smooth endoplasmic reticulum or mitochondria, located near labeled portions of the plasma membrane. In sections processed for dual labeling, Dyn-containing terminals rarely $(<1 \%)$ contacted KOR-immunoreactive somata and dendrites. Dyn and KOR immunoreactivities rarely $(<1 \%)$ were seen within the same cell body or dendrite.

\section{KOR immunoreactivity is localized to a few glial processes}

Ten percent of the KOR-labeled profiles were astrocytic processes ( $n=85$ of 851 KOR-immunoreactive profiles), as defined by their irregular contour and/or intermediate filaments (Peters et al., 1991). Intense peroxidase labeling for KOR was seen mainly along plasma membranes of glial processes interposed at excitatory-type synapses on dendritic spines (Fig. 4C). The labeling was selective in that other astrocytic processes, some of which formed gap junctions with those containing KOR immunoreac- 

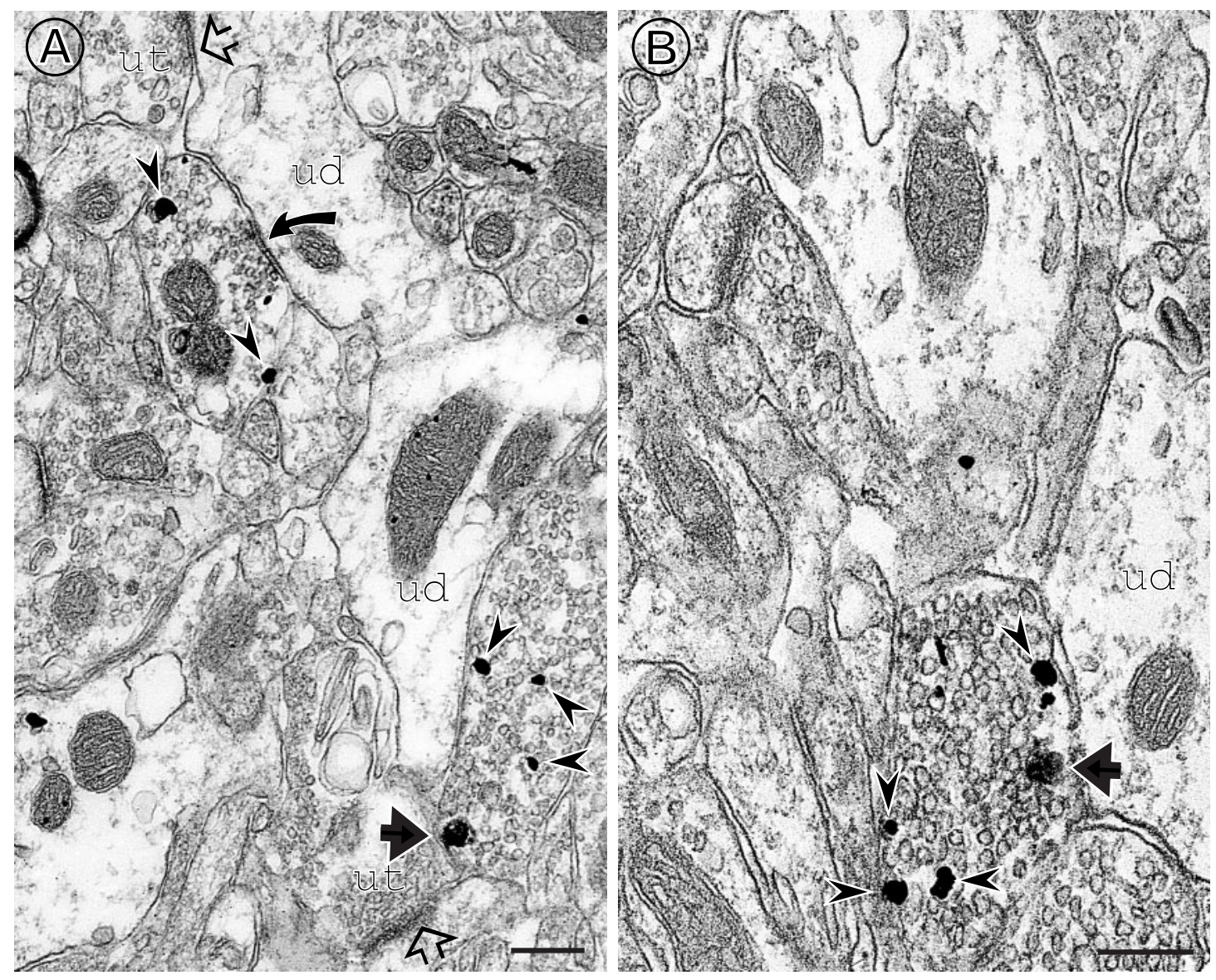

Figure 3. Immunoperoxidase labeling for KOR in cytoplasmic granules within axon terminals that contain Dyn. The peroxidase reaction product for KOR (small filled arrows) is intensely and selectively localized to large vesicles located near contact with an unlabeled terminal forming an asymmetric axospinous synapse in $A$ and with an unlabeled dendrite in $B$. Gold-silver particles for Dyn (arrowheads) are more randomly dispersed within the cytoplasm. The dually labeled axon terminal in $A$ is also apposed to an unlabeled dendrite $(u d)$. In this electron micrograph $(A)$, another Dyn-containing terminal forms a symmetric synapse (curved arrow) with a $u d$. This dendrite receives convergent synaptic input (open arrows) from an unlabeled terminal $(u t)$. Scale bars, $0.24 \mu \mathrm{m}$.

tivity, were unlabeled (Fig. 4C). KOR immunoreactivity was also associated with glial filaments.

\section{DISCUSSION}

Our results identified axon terminals as the primary site for KOR modulation of neurotransmission in the AcbSh. We show the presence of KOR in (1) small axons and terminals having the morphological features of dopamine- or acetylcholine-containing neurons and in (2) larger axon terminals that either contained Dyn or formed excitatory-type synapses. This suggests that in the AcbSh, KOR plays a primary role in modulating the secretion of neuromodulators, including Dyn, and to a lesser extent presynaptically modulates the release of excitatory amino acids. At excitatory-type synapses, we also observed KOR labeling within postsynaptic spines and in apposing astrocytes. Together these results suggest that within this region the changes in excitatory transmission evoked via KOR activation involve not only presyn- aptic release but postsynaptic responses and possibly glial uptake of glutamate.

\section{Methodological considerations}

The term KOR-LI is used to describe the localization of the anti-peptide antiserum used in this study and includes the possibility that the antiserum may recognize structurally similar proteins. On the basis of several lines of evidence, however, we believe that the antiserum specifically recognizes KOR (Drake et al., 1996; Appleyard et al., 1997).

Avidin-biotin-peroxidase labeling is known to diffuse, which may lead to artifactual labeling (Beier, 1992). Despite this limitation, the peroxidase reaction product is highly sensitive and therefore is able to detect discrete subcellular patterns of receptor immunoreactivity. The relative number of somata and large dendrites containing Dyn and KOR immunoreactivity is likely to be underrepresented, because Dyn is present in comparatively

association with extrasynaptic portions of the plasma membrane (lower small filled arrows). The KOR-labeled spine receives synaptic input from a ut. In the same field, a KOR-labeled axon (upper small filled arrow) apposes an unlabeled spine (us) that receives an asymmetric synapse (open arrow) from a ut. $C$, KOR immunoreactivity is localized along the plasma membrane and diff usely distributed within the cytoplasm of astrocytic processes (asterisks). KOR labeling also is seen along a gap junction (curved arrow), with an unlabeled glial process. Open arrows are as in $B$. Scale bars, $0.2 \mu \mathrm{m}$. 


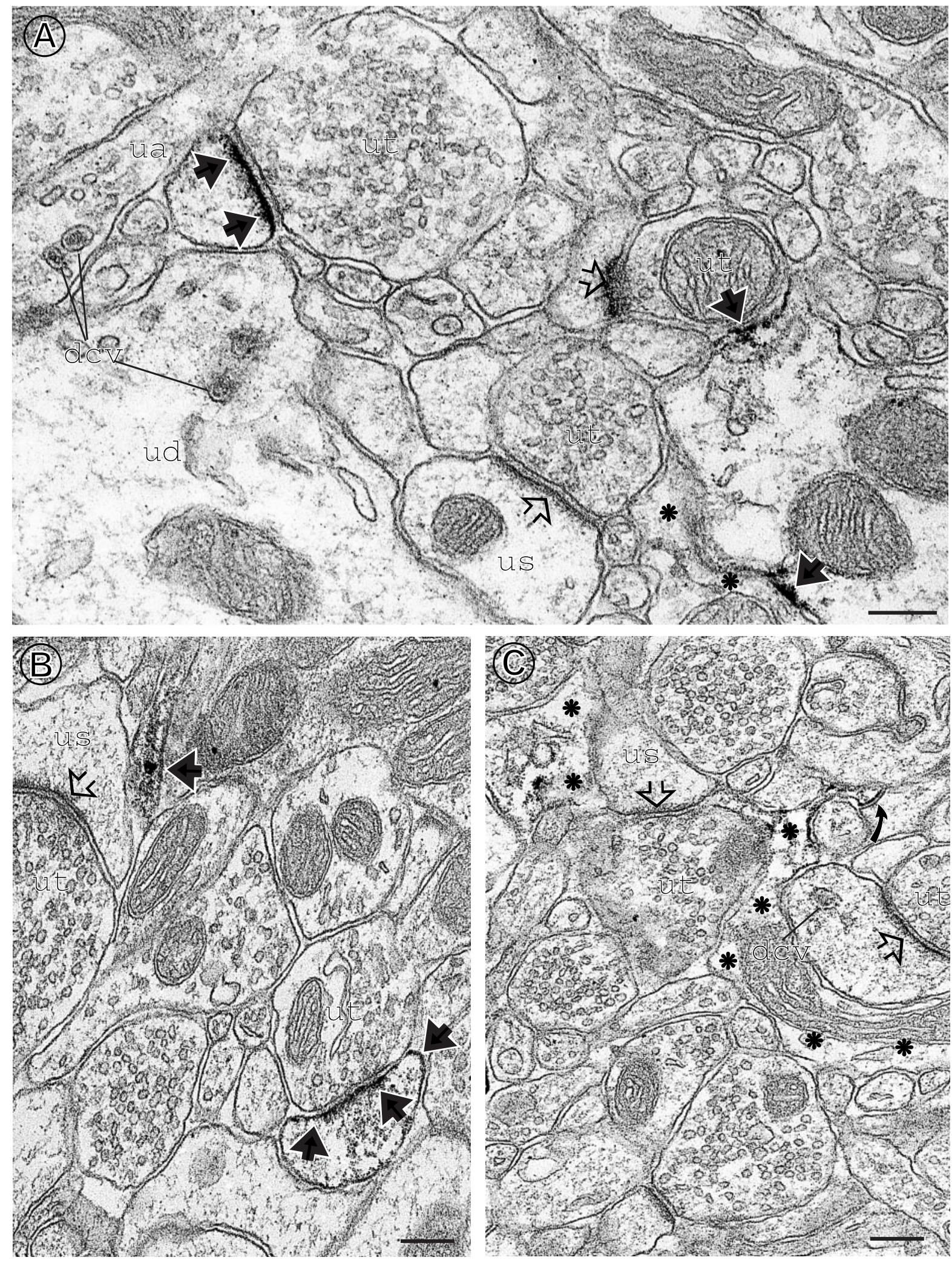

Figure 4. Immunoperoxidase labeling for KOR within dendrites, dendritic spines, and glial processes. $A$, KOR immunoreactivity is localized to selective plasmalemmal portions of a large dendrite and a dendritic spine. The most intense labeling in the dendrite (lower small filled arrows) is near (1) an appositional contact with an unlabeled terminal (ut) forming an asymmetric axospinous synapse (open arrow) and (2) a glial process (asterisks). Within the spine, the immunoreactivity is seen along an asymmetric postsynaptic density (upper small filled arrows) that is formed by a ut. The KOR-labeled spine also apposes an unlabeled axon $(u a)$ and an unlabeled dendrite $(u d)$ that contain dense core vesicles $(d c v s)$. $B$, A dendritic spine contains diffuse immunoperoxidase reaction for KOR. The most intense labeling is seen along the postsynaptic density and in (Figure legend continues on preceding page) 

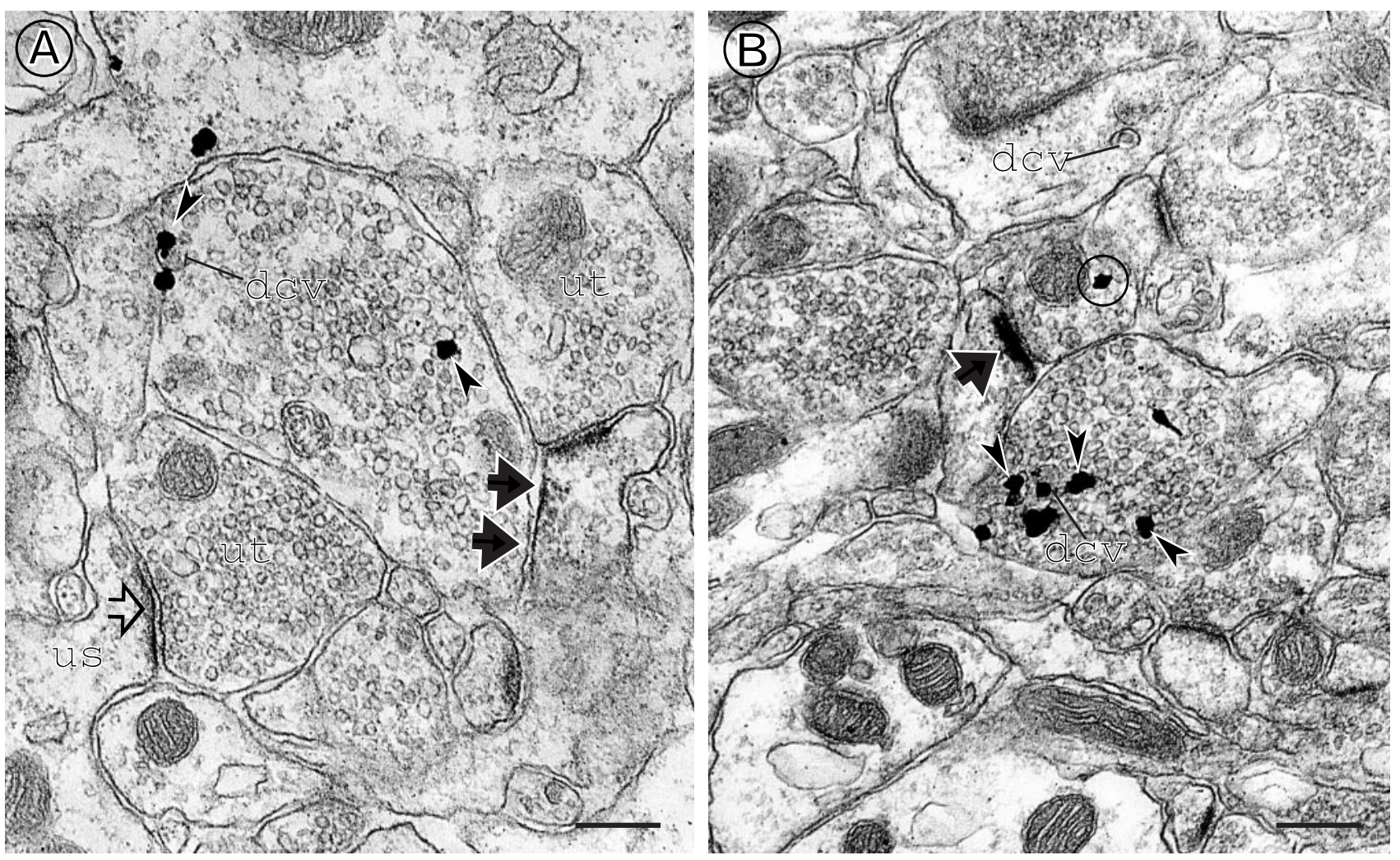

Figure 5. Immunoperoxidase labeling for KOR in dendritic spines that are postsynaptic to unlabeled terminals and are apposed to Dyn-containing terminals. $A$, KOR immunoreactivity is localized to extrasynaptic plasmalemmal portions (small filled arrows) of a dendritic spine. $B$, KOR labeling seen more exclusively at the postsynaptic density (small filled arrow) of the spine. Both spines $(A, B)$ receive asymmetric synapses from unlabeled terminals $(u t)$ and are apposed to terminals that contain immunogold-silver for Dyn (arrowheads). Some gold particles in $A$ and $B$ are clustered over dense core vesicles $(d c v)$. The gold particle in the unlabeled terminal forming an asymmetric synapse with the KOR-labeled spine in $B$ (circled) is below the number of particles used for positive identification of Dyn terminals. $A$, An unlabeled terminal (ut) forms an asymmetric synapse (open arrow) with an unlabeled spine (us). Scale bars, $0.2 \mu \mathrm{m}$.

low amounts in nonaxonal structures without the use of colchicine or other mitotic inhibitors to block axonal transport (Bayon et al., 1979).

\section{KOR immunoreactivity is localized to morphologically diverse axon terminals}

We observed a similar subcellular distribution of KOR immunoreactivity among terminals having diverse morphological features. The plasma membranes of axons showed intense KOR labeling, providing possible sites for receptor-mediated attenuation of presynaptic neurotransmission via changes in calcium or potassium conductance (Gross and MacDonald, 1987; Grudt and Williams, 1993; Moore et al., 1994). In this regard, N-type calcium channels, which couple to KOR and regulate transmitter release (Xiang et al., 1990; Rhim and Miller, 1994), are localized to axon terminals (Westenbroek et al., 1992). KOR also was frequently localized to SSVs, suggesting a mechanism for receptor transport to functional sites and receptor recycling (Broadwell and Cataldo, 1983; Smythe and Warren, 1991). The distribution along plasma membranes in morphologically diverse axon terminals suggests that the labeling represents functional sites at which KOR plays a role in the regulated release of one or more neurotransmitters.

Most KOR-immunoreactive axon terminals were small, forming either nonrecognizable or poorly differentiated symmetric junctions. These morphological characteristics are similar to those described for catecholaminergic and cholinergic terminals (Houser et al., 1983; Wainer et al., 1984; Phelps et al., 1985; Pickel and Chan, 1990). These observations support the possibility of KOR localization within dopaminergic terminals, consistent with studies showing that KOR agonists decrease basal and evokedextracellular dopamine levels in the striatum and that KOR activation is dopamine dependent (Di Chiara and Imperato, 1988; Spanagel et al., 1990; Shippenberg et al., 1993). The morphological profile of KOR-immunoreactive terminals also supports evidence showing that KOR agonists decrease presynaptic cholinergic transmission (Lapchak et al., 1989; Schoffelmeer et al., 1997). Furthermore, KOR-labeled terminals contacted targets that also received input from terminals forming excitatory synapses. Thus, changes in extracellular dopamine or acetylcholine levels would most likely influence postsynaptic responses but also may diffuse to alter presynaptic excitatory transmission.

KOR-immunoreactive terminals more rarely formed asymmetric axospinous synapses, typical of glutamatergic terminals (Hendry et al., 1983). The localization of KOR to these terminals is consistent with studies showing that KOR ligands modulate extracellular levels of glutamate (Wagner et al., 1992; Simmons et al., 1994; Rawls and McGinty, 1998). The relatively small number of KOR-containing terminals forming asymmetric synapses in the present study suggests that the direct effects of KOR agonists on glutamate release are relatively minor. Instead, we expect that as 
discussed above, the effects of KOR agonists on extracellular glutamate are indirectly mediated via changes in neuromodulator release. We cannot, however, exclude the possibility that undetectably low levels of KOR are present in excitatory terminals. The receptor might also be present in larger proportions in presynaptic axons of excitatory terminals, which only would be seen in longitudinal sections. In addition, KOR-mediated fluctuations in extracellular glutamate may reflect changes in astrocytic reuptake (Eriksson et al., 1993; Ruzicka et al., 1995; Gurwell et al., 1996). A role for KOR in these neuron-glia interactions is suggested by our data showing KOR-immunoreactive astrocytes interspersed among terminals forming asymmetric synapses.

\section{KOR is present in axon terminals that either appose Dyn-labeled terminals or contain Dyn}

The majority of KOR-labeled axons in the AcbSh were not in contact with Dyn-containing terminals, supporting the idea that neuropeptides diffuse from release sites to activate more distant receptors (Thureson-Klein and Klein, 1990; Drake et al., 1994). A few KOR-labeled axons and terminals, however, directly apposed Dyn-containing terminals. Apposing Dyn-labeled terminals were large, contained DCVs and formed symmetric synapses with unlabeled dendrites. Synaptic specializations between KORand Dyn-labeled terminals were not observed, consistent with the low incidence of axoaxonic synapses in the striatum (Kemp and Powell, 1971). Our data provide anatomical evidence of an endogenous source of KOR activation but indicate that Dyn is not necessarily released near sites of functional activation.

KOR and Dyn immunoreactivities were colocalized within axon terminals. As reported previously, both antigens were localized to DCVs (Thureson-Klein and Klein, 1990; Drake et al., 1996). These data indicate that KOR and Dyn may be transported to functional sites under similar conditions (Schwarzenbrunner et al., 1990; Drake et al., 1996). Dually labeled terminals were large and formed symmetric synapses with dendrites, consistent with the localization of KOR to Dyn-containing neurons containing substance P or GABA (Pickel et al., 1988; Van Bockstaele et al., 1995; Drake et al., 1997a). These data suggest that KOR may be a presynaptic autoreceptor, regulating the release of Dyn or other transmitters (Gannon and Terrian, 1991).

\section{KOR immunoreactivity is present in dendritic spines, which appose Dyn-labeled terminals}

We observed KOR immunoreactivity within asymmetric postsynaptic densities and extrasynaptic portions of plasma membranes within dendritic spines. These data suggest that KOR ligands modulate the postsynaptic responsivity of spiny neurons, possibly via changes in potassium or calcium channel conductance (Moore et al., 1994; Simmons et al., 1995). Interestingly, GIRK1, a Gprotein-activated inward-rectifying potassium channel that couples to KOR in vitro (Henry et al., 1995), also is highly localized within dendritic spines (Drake et al., 1997b). In addition, our data provide an anatomical substrate for pharmacological studies, which predict that KOR ligands can alter postsynaptic responses via regulation of NMDA or AMPA/kainate receptor function (Caudle et al., 1994; Kolaj et al., 1995). In this regard, the postsynaptic localization of NMDA receptors in the AcbSh is similar to that of KOR (Gracy et al., 1997). These results suggest that dendritic spines subserve KOR alterations of glutamatergic transmission via modulation of ion channel flux or synaptic currents.

KOR-labeled spines usually were not contacted by Dyn- containing terminals, consistent with the lack of direct association observed between KOR- and Dyn-labeled axon terminals. These data support the hypothesis that opioid receptors are activated nonsynaptically by peptides that are released into the extracellular space (Jan and Jan, 1983; Herkenham, 1987; Pickel et al., 1995). There were, however, instances of direct apposition between Dyn-labeled terminals and KOR-immunoreactive spines. Presumably, those spines in direct contact with Dyn-containing terminals could detect small variations in peptide release.

\section{Functional implications}

Our results provide the first ultrastructural evidence that KOR has a heterogenous cellular distribution consistent with involvement in the direct and indirect modulation of excitatory transmission within the AcbSh. The present findings indicate that the functional sites of KOR activation are mainly axon terminals containing neuromodulators, such a dopamine, but also include postsynaptic spines and glia. Although previous localizations of DOR and MOR in the AcbSh (Svingos et al., 1996, 1998) suggest that these receptors may also play a major role in determining the output from the ventral striatum, their primary sites of activation show notable differences from that of KOR. DOR is mainly localized to nondopamine-containing terminals that form punctate-symmetrical and appositional contacts, consistent with DOR-mediated modulation of acetylcholine release (Heijna et al., 1990; Svingos et al., 1998) (A. L. Svingos and V. M. Pickel, unpublished observations). The prominent localization of MOR to GABA-containing neurons provides an anatomical substrate for the disinhibitory actions of striatal opioids (Johnson and North, 1992; Yuan et al., 1992; Svingos et al., 1997). These data indicate that modulation of excitatory and inhibitory transmission in the AcbSh is subserved by opioids that target their respective receptors at differential cellular sites. In contrast, the proportion of KOR-LI within dendritic spines in the present study is similar to that of DOR and MOR. This suggests a common postsynaptic site for modulation of glutamatergic transmission within spiny projection neurons, a neuronal population critical for the expression of opiate-induced aversion via KOR, as well as the reward associated with DOR and MOR (Zito et al., 1985; Hubner and Koob, 1990).

\section{REFERENCES}

Appleyard SM, Patterson TA, Jin WZ, Chavkin C (1997) Agonistinduced phosphorylation of the kappa-opioid receptor. J Neurochem 69:2405-2412.

Arvidsson U, Riedl M, Chakrabarti S, Vulchanova L, Lee J-H, Nakano AH, Lin X, Loh HH, Law P-Y, Wessendorf MW, Elde R (1995) The $\kappa$-opioid receptor is primarily postsynaptic: combined immunohistochemical localization of the receptor and endogenous opioids. Proc Natl Acad Sci USA 92:5062-5066.

Attali B, Saya D, Nah S-Y, Vogel Z (1989) $к$ Opiate agonists inhibit $\mathrm{Ca}^{2+}$ influx in rat spinal cord-dorsal root ganglion cocultures. Involvement of a GTP-binding protein. J Biol Chem 264:347-353.

Bals-Kubik R, Ableitner A, Herz A, Shippenberg TS (1993) Neuroanatomical sites mediating the motivational effects of opioids as mapped by the conditioned place preference paradigm in rats. J Pharmacol Exp Ther 264:489-495.

Bayon A, Koda L, Battenberg E, Bloom FE (1979) Redistribution of endorphin and enkephalin immunoreactivity in rat brain and pituitary after in vivo treatment with colchicine and cytochalasin B. Brain Res 183:101-111.

Beier K (1992) Light microscopic morphometric analysis of peroxisomes by automatic image analysis: advantages of immunostaining over the alkaline DAB method. J Histochem Cytochem 40:115-121.

Broadwell RD, Cataldo AM (1983) The neuronal endoplasmic reticulum: its cytochemistry and contribution to the endomembrane system. J Histochem Cytochem 31:1077-1088. 
Carlin RK, Grab DJ, Cohen RS, Siekovitz P (1980) Isolation and characterization of postsynaptic densities from various brain regions. J Cell Biol 86:831-843.

Caudle RM, Chavkin C, Dubner R (1994) $\kappa_{2}$ Opioid receptors inhibit NMDA receptor-mediated synaptic currents in guinea pig CA3 pyramidal cells. J Neurosci 14:5580-5589.

Chan J, Aoki C, Pickel VM (1990) Optimization of differential immunogold-silver and peroxidase labeling with maintenance of ultrastructure in brain sections before plastic embedding. J Neurosci Methods 33:113-127.

Chavkin C, James IF, Goldstein A (1982) Dynorphin is a specific endogenous ligand of the $\kappa$ opioid receptor. Science 215:413-415.

Di Chiara G, Imperato A (1988) Drugs abused by humans preferentially increase synaptic dopamine concentrations in the mesolimbic system of freely moving rats. Proc Natl Acad Sci USA 85:5274-5278.

Drake CT, Terman GW, Simmons ML, Milner TA, Kunkel DD, Schwartzkroin PA, Chavkin C (1994) Dynorphin opioids present in dentate granule cells may function as retrograde inhibitory neurotransmitters. J Neurosci 14:3736-3750.

Drake CT, Patterson TA, Simmons ML, Chavkin C, Milner TA (1996) Kappa opioid receptor-like immunoreactivity in guinea pig brain: ultrastructural localization in presynaptic terminals in hippocampal formation. J Comp Neurol 370:377-395.

Drake CT, Chavkin C, Milner TA (1997a) Kappa opioid receptor-like immunoreactivity is present in substance P-containing subcortical afferents in guinea pig dentate gyrus. Hippocampus 7:36-47.

Drake CT, Bausch SB, Milner TA, Chavkin C (1997b) GIRK1 immunoreactivity is present in somata, dendrites, and dendritic spines in the CA1 region of the hippocampus. Proc Natl Acad Sci USA 94:1007-1012.

Eriksson PS, Nilsson M, Wagberg M, Hansson E, Ronnback L (1993) Kappa-opioid receptors on astrocytes stimulate $\mathrm{L}$-type $\mathrm{Ca}^{2+}$ channels. Neuroscience 54:401-407.

Fallon J, Leslie F (1986) Distribution of dynorphin and enkephalin peptides in the rat brain. J Comp Neurol 249:293-336.

Fan SF, Shen KF, Crain SM (1991) Opioids at low concentrations decrease openings of $\mathrm{K}^{+}$channels in sensory ganglion neurons. Brain Res 558:166-170

Funada M, Suzuki T, Narita M, Misawa M, Nagase H (1993) Blockade of morphine reward through the activation of kappa-opioid receptors in mice. Neuropharmacology 32:1315-1323.

Gannon RL, Terrian DM (1991) U-50,488H inhibits dynorphin and glutamate release from guinea pig hippocampal mossy fiber terminals. Brain Res 548:242-247.

Gracy KN, Svingos AL, Pickel VM (1997) Dual ultrastructural localization of $\mu$-opioid receptors and NMDA-type glutamate receptors in the shell of the rat nucleus accumbens. J Neurosci 17:4839-4848.

Gross RA, MacDonald RL (1987) Dynorphin A selectively reduces a large transient (N-type) calcium current of mouse dorsal root ganglion neurons in cell culture. Proc Natl Acad Sci USA 84:5469-5473.

Grudt TJ, Williams JT (1993) $\kappa$-Opioid receptors also increase potassium conductance. Proc Natl Acad Sci USA 90:11429-11432.

Gurwell JA, Duncan MJ, Maderspach K, Stiene-Martin A, Elde R, Hauser KF (1996) $\kappa$-Opioid receptor expression defines a phenotypically distinct subpopulation of astroglia: relationship to $\mathrm{Ca}^{2+}$ mobilization, development, and the antiproliferative effect of opioids. Brain Res 737:175-117.

Heijna MH, Padt M, Hogenboom F, Porthoghese PS, Mulder AH, Schoffelmeer ANM (1990) Opioid receptor-mediated inhibition of dopamine and acetylcholine release from rat brain slices: differences between nucleus accumbens, olfactory tubercle and frontal cortex in receptor types involved. Eur J Pharmacol 181:267-278.

Heijna MH, Hogenboom F, Mulder AH, Schoffelmeer ANM (1992) Opioid receptor-mediated inhibition of $3 \mathrm{H}$-dopamine and $14 \mathrm{C}$ acetylcholine release from rat nucleus accumbens slices. A study on the possible involvement of $\mathrm{K}+$ channels and adenylate cyclase. Naunyn Schmiedebergs Arch Pharmacol 345:627-632.

Hendry SHC, Houser CR, Jones EG, Vaughn JE (1983) Synaptic organization of immunocytochemically identified GABA neurons in the monkey sensory-motor cortex. J Neurocytol 12:639-660.

Henry DJ, Grandy DK, Lester HA, Davidson N, Chavkin C (1995) Kappa-opioid receptors couple to inwardly rectifying potassium channels when coexpressed by Xenopus oocytes. Mol Pharmacol 47:551-557.

Herkenham M (1987) Mismatches between neurotransmitter and recep- tor localizations in brain: observations and implications. Neuroscience 23:1-38.

Houser CR, Crawford GD, Barber RP, Salvaterra PM, Vaughn JE (1983) Organization and morphological characteristics of cholinergic neurons: an immunocytochemical study with a monoclonal antibody to choline acetyltransferase. Brain Res 266:97-119.

Hsu S-M, Raine L, Fanger H (1981) Use of avidin-biotin-peroxidase complex (ABC) immunoperoxidase techniques: a comparison between $\mathrm{ABC}$ and unlabeled antibody (PAP) procedures. J Histochem Cytochem 29:577-580.

Hubner CB, Koob GF (1990) The ventral pallidum plays a role in mediating cocaine and heroin self-administration in the rat. Brain Res 508:20-29.

Jan YN, Jan LY (1983) A LHRH-like peptidergic neurotransmitter capable of "action at a distance" in autonomic ganglia. Trends Neurosci 6:320-325.

Johnson SW, North RA (1992) Opioids excite dopamine neurons by hyperpolarization of local interneurons. J Neurosci 12:483-488.

Jomary C, Gairin JE, Beaudet A (1992) Synaptic localization of $\kappa$ opioid receptors in guinea pig neostriatum. Proc Natl Acad Sci USA 89:564-568.

Kemp JM, Powell TPS (1971) The synaptic organization of the caudate nucleus. Philos Trans R Soc Lond [Biol] 262:403-412.

Kolaj M, Cerne R, Randic M (1995) The opioid peptide dynorphin modulates AMPA and kainate responses in acutely isolated neurons from the dorsal horn. Brain Res 671:227-244.

Lapchak PA, Araujo DM, Collier B (1989) Regulation of endogenous acetylcholine release from mammalian brain slices by opiate receptors: hippocampus, striatum and cerebral cortex of guinea-pig and rat. Neuroscience 31:313-325.

Leranth C, Pickel VM (1989) Electron microscopic pre-embedding double immunostaining methods. In: Tract tracing methods 2 , recent progress (Heimer L, Zaborsky L, eds), pp 129-172. New York: Plenum.

Mansour A, Khachaturian H, Lewis ME, Akil H, Watson SJ (1987) Autoradiographic differentiation of mu, delta and kappa opioid receptors in the rat forebrain and midbrain. J Neurosci 7:2445-2464.

Mansour A, Burke S, Pavlic RJ, Akil H, Watson SJ (1996) Immunohistochemical localization of the cloned kappa $_{1}$ receptor in the rat CNS and pituitary. Neuroscience 71:671-690.

McGinty JF, Bohler WT, Patterson TA, Chavkin C (1994) Kappa opioid receptor immunoreactivity is present in cells and fibers of the rat forebrain. Regul Pept 54:185-186.

Moore SC, Madamba SG, Schweitzer P, Siggins GR (1994) Voltagedependent effects of opioid peptides on hippocampal CA3 pyramidal neurons in vitro. J Neurosci 14:809-820.

Mulder AH, Wardeh G, Hogenboom F, Frankhuyzen AL (1984) Kappa and delta-opioid receptor agonists differentially inhibit striatal dopamine and acetylcholine release. Nature 308:278-280.

Mulder AH, Wardeh G, Hogenboom F, Frankhuyzen AL (1989) Selectivity of various opioid peptides towards delta-, kappa- and mu-opioid receptors mediating presynaptic inhibition of neurotransmitter release in the brain. Neuropeptides 14:99-104.

Paxinos G, Watson C (1986) The rat brain in stereotaxic coordinates. New York: Academic.

Pearl SM, Glick SD (1996) Prolonged antagonism of morphine-induced locomotor stimulation by kappa opioid agonists: enhancement by prior morphine exposure. Neurosci Lett 213:5-8.

Peters A, Palay SL, Webster H deF (1991) The fine structure of the nervous system, neurons and their supporting cells, 3rd Edition. New York: Oxford UP.

Phelps PE, Houser CR, Vaughn JE (1985) Immunocytochemical localization of choline acetyltransferase within the rat neostriatum: a correlated light and electron microscopic study of cholinergic neurons and synapses. J Comp Neurol 238:286-307.

Pickel VM, Chan J (1990) Spiny neurons lacking choline acetyltransferase immunoreactivity are major targets of cholinergic and catecholaminergic terminals in rat striatum. J Neurosci Res 25:263-280.

Pickel VM, Joh TH, Chan J (1988) Substance P in the rat nucleus accumbens: ultrastructural localization in axon terminals and their relation to dopaminergic afferents. Brain Res 444:247-264.

Pickel VM, Chan J, Veznedaroglu E, Milner TA (1995) Neuropeptide Y and dynorphin-immunoreactive large dense-core vesicles are strategically localized for presynaptic modulation in the hippocampal formation and substantia nigra. Synapse 19:160-169.

Rawls SM, McGinty JF (1998) Kappa receptor activation attenuates 
L-trans-pyrrolidine-2,4-dicarboxylic acid-evoked glutamate levels in the striatum. J Neurochem 70:626-634.

Reynolds ES (1963) The use of lead citrate at high $\mathrm{pH}$ as an electronopaque stain in electron microscopy. J Cell Biol 17:208.

Rhim H, Miller RJ (1994) Opioid receptors modulate diverse types of calcium channels in the nucleus tractus solitarius of the rat. J Neurosci 14:7608-7615.

Ruzicka BB, Fox CA, Thompson RC, Meng F, Watson SJ, Akil H (1995) Primary astroglial cultures derived from several rat brain regions differentially expresses $\mu, \delta$ and $\kappa$ opioid receptor mRNA. Mol Brain Res 34:209-220.

Schoffelmeer AN, Hogenboom F, Mulder AH (1997) Kappa1- and kappa2-opioid receptors mediating presynaptic inhibition of dopamine and acetylcholine release in the rat neostriatum. $\mathrm{Br} \mathrm{J}$ Pharmacol 122:520-524.

Schwarzenbrunner U, Schmidle T, Obendorf D, Scherman D, Hook V, Fischer CR, Winkler H (1990) Sympathetic axons and nerve terminals: the protein composition of small and large dense-core and of a third type of vesicle. Neuroscience 37:819-827.

Shippenberg TS, Bals-Kubik R, Herz A (1993) Examination of the neurochemical substrates mediating the motivational effects of opioids: role of the mesolimbic dopamine system and D-1 vs. D-2 dopamine receptors. J Pharmacol Exp Ther 265:53-59.

Shippenberg TS, LeFevour A, Heidbreder Ch (1996) $\kappa$-Opioid receptor agonists prevent sensitization to the conditioned rewarding effects of cocaine. J Pharmacol Exp Ther 276:545-554.

Simmons ML, Terman GW, Drake CT, Chavkin C (1994) Inhibition of glutamate release by presynaptic $\kappa_{1}$-opioid receptors in the guinea pig dentate gyrus. J Neurophysiol 72:1697-1705.

Simmons ML, Terman GW, Gibbs SM, Chavkin C (1995) L-type calcium channels mediate dynorphin neuropeptide release from dendrites but not axons of hippocampal granule cells. Neuron 14:1265-1272.

Smythe E, Warren G (1991) The mechanism of receptor-mediated endocytosis. Eur J Biochem 202:689-699.

Spanagel R, Herz A, Shippenberg TS (1990) The effects of opioid peptides on dopamine release in the nucleus accumbens: an in vivo microdialysis study. J Neurochem 55:1734-1740.

Spanagel R, Herz A, Shippenberg TS (1992) Opposing tonically active endogenous opioid systems modulate the mesolimbic dopaminergic pathway. Proc Natl Acad Sci USA 89:2046-2050.

Spanagel R, Almeida OF, Bartl C, Shippenberg TS (1994) Endogenous kappa-opioid systems in opiate withdrawal: role in aversion and accom- panying changes in mesolimbic dopamine release. Psychopharmacology (Berl) 115:121-127.

Svingos AL, Moriwaki A, Wang JB, Uhl GR, Pickel VM (1996) Ultrastructural immunocytochemical localization of $\mu$-opioid receptors in rat nucleus accumbens: extrasynaptic plasmalemmal distribution and association with Leu ${ }^{5}$-enkephalin. J Neurosci 16:4162-4173.

Svingos AL, Moriwaki A, Wang JB, Uhl GR, Pickel VM (1997) $\mu$-Opioid receptors are localized to extrasynaptic plasma membranes of GABAergic neurons and their targets in the rat nucleus accumbens. J Neurosci 17:2585-2594.

Svingos AL, Clarke CL, Pickel VM (1998) Cellular sites for activation of $\delta$-opioid receptors in the rat nucleus accumbens shell: relationship with Met ${ }^{5}$-enkephalin. J Neurosci 18:1923-1933.

Tempel A, Zukin S (1987) Neuroanatomical patterns of the $\mu, \delta$, and $\kappa$ opioid receptors of rat brain as determined by quantitative in vitro autoradiography. Proc Natl Acad Sci USA 84:4208-4312.

Thureson-Klein AK, Klein RL (1990) Exocytosis from neuronal large dense-cored vesicles. Int Rev Cytol 121:67-126.

Van Bockstaele EJ, Gracy KN, Pickel VM (1995) Dynorphinimmunoreactive neurons in the rat nucleus accumbens: ultrastructure and synaptic input from terminals containing substance $\mathrm{P}$ and/or dynorphin. J Comp Neurol 351:117-133.

Wagner JJ, Caudle RM, Chavkin C (1992) Kappa-opioids decrease excitatory transmission in the dentate gyrus of the guinea pig hippocampus. J Neurosci 12:132-141.

Wainer BH, Bolam JP, Freund TF, Henderson Z, Totterdell S, Smith AD (1984) Cholinergic synapses in the rat brain: a correlated light and electron microscopic immunohistochemical study employing a monoclonal antibody against choline acetyltransferase. Brain Res 308:69-76.

Westenbroek RE, Hell JW, Warner C, Dubel SJ, Snutch TP, Catterall WA (1992) Biochemical properties and subcellular distribution of an N-type calcium channel $\alpha_{1}$ subunit. Neuron 9:1099-1115.

Xiang J-Z, Adamson P, Brammer MJ, Campbell IC (1990) The $\kappa$-opiate agonist U50488H decreases the entry of calcium into rat cortical synaptosomes by inhibiting $\mathrm{N}$ - but not L-type calcium channels. Neuropharmacology 295:439-444.

Yuan X, Madamba S, Siggins GR (1992) Opioid peptides reduce synaptic transmission in the nucleus accumbens. Neurosci Lett 134:223-228.

Zito KA, Vickers G, Roberts DC (1985) Disruption of cocaine and heroin self-administration following kainic acid lesions of the nucleus accumbens. Pharmacol Biochem Behav 23:1029-1036. 